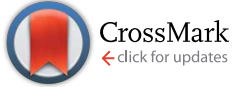

Cite this: RSC Adv., 2017, 7, 13768

\title{
Co-liquefaction of microalgae and polypropylene in sub-/super-critical water $\dagger$
}

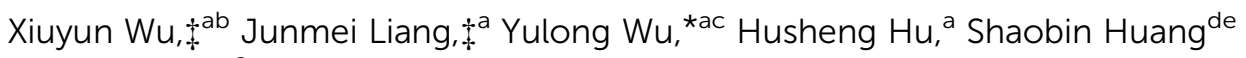 \\ and Kejing $\mathrm{Wu}^{\mathrm{a}}$
}

In the current study, Dunaliella tertiolecta (D. tertiolecta) and polypropylene (PP) were chosen to investigate the co-liquefaction process of microalgae and plastic. The results show that a maximum synergistic effect was found when the mass ratio of $D$. tertiolecta to PP was $8: 2$. The addition of PP mainly impacts the composition of the bio-oil products, particularly reducing the acid content. When $D$. tertiolecta was liquefied individually, the relative content of acid in bio-oil could reach $18.73 \%$, while for $D$. tertiolecta and PP co-liquefaction in a ratio of $8: 2$, the acid content of bio-oil was lower than the detection limit of GC-MS (lower than 100 ppm). The reaction mechanism for the co-liquefaction process of PP and the main components of microalgae has also been studied. The addition of PP has a significant effect on the transformation pathways of carbohydrates in microalgae, and this also promotes the Maillard reaction between carbohydrates and proteins or their hydrolysates.

Received 23rd January 2017

DOI: $10.1039 / c 7 r a 01030 c$

rsc.li/rsc-advances there are two main pathways to improve the quality of bio-oil: (1) high-pressure hydrogenation processing and catalytic cracking $^{7}$ and (2) co-processing (including co-pyrolysis and coliquefaction processes) of biomass with other materials such as coal, domestic garbage and plastic. ${ }^{8}$ The latter has received increasing attention in recent years. Since plastics like polyethylene (PE) and polypropylene (PP) contain a large amount of hydrogen (approximately 14 wt\%), its co-processing with biomass can provide hydrogen, which can lead to an increase of liquid yield and improvement in the oil quality. ${ }^{9}$ Moreover, high-pressure hydrogenation in the subsequent upgrading process can be avoided. In addition, co-processing can also handle waste plastic efficiently, which is the major source of white pollution. To this end, the co-processing has broad application prospects.

In recent years, some studies concerning the co-pyrolysis and co-liquefaction of plastic and terrestrial biomass materials (the main ingredients being cellulose, hemicellulose and lignin) have been published reporting the efforts to reduce the decomposition temperature of plastic. The results show that the key to the interaction between plastic and biomass was whether the decomposition temperature ranges of the co-processed materials could be overlapped. ${ }^{10}$ The decomposition temperature of plastic is generally higher than $400{ }^{\circ} \mathrm{C}$, and the decomposition temperature of lignin is also about $400{ }^{\circ} \mathrm{C} .{ }^{11}$ Sørum et al. ${ }^{12}$ confirmed that the co-pyrolysis of plastic and terrestrial biomass material can produce high quality fuel oil or high value chemicals. However, the co-processing of plastic and microalgae has been rarely investigated to date. Wu et al. ${ }^{13}$ found that the lipid compounds in microalgae undergo pyrolysis after $380{ }^{\circ} \mathrm{C}$. This indicates that the decomposition temperatures of microalgae 
and plastic overlapped. Therefore, it is possible to improve the quality of bio-oil by adding plastic into the thermochemical conversion process of microalgae. In a previous study, ${ }^{14}$ we studied the kinetics of the co-pyrolysis of microalgae and plastic and found that their interaction can decrease the pyrolysis activation energy of microalgae. The two studies described above and by our group were carried out using thermogravimetric analysis (TGA), and the experimental conditions were very similar to those of the pyrolysis process. Due to extremely high water content in microalgae feedstocks, liquefaction is much better than pyrolysis for algal conversion. However, only limited studies on the co-liquefaction of microalgae and plastics have been published, compared to those on co-pyrolysis. Pei et al. ${ }^{15}$ and Duan $e$ t al. ${ }^{16}$ have studied the co-liquefaction of microalgae with high density PE and waste rubber tires in supercritical ethanol, respectively, and have found a positive synergistic effect with the two reactants. Considering that water is the cheapest and most environmentally friendly medium, and the fact that microalgae grow in water and contain a large amount of water, the co-liquefaction of microalgae with plastic in water, rather than an organic solvent, is potentially the most promising process and is yet to be reported.

The interaction between microalgae and plastics can increase the yield and quality of bio-oil, but there are only a few reports on the mechanism and process of the interaction between the two, particularly on the hydrothermal liquefaction (HTL) process. The objective of this study is to study the interaction between plastic (PP) and microalgae (D. tertiolecta) in the HTL process and probe the possible reaction mechanism through the analysis of the composition of bio-oil obtained with different operating conditions.

\section{Materials and methods}

\subsection{Materials}

D. tertiolecta (Xi'an Victory Biochemical Co. China) and PP (Shanghai Yangli Electromechanical Science and Technology LTD., China) were used in this study. The microalgae were dried at $105{ }^{\circ} \mathrm{C}$ for $24 \mathrm{~h}$, ground and sieved to obtain a fraction under 120 mesh $(<125 \mu \mathrm{m})$, while PP was dried at $80{ }^{\circ} \mathrm{C}$ for $24 \mathrm{~h}$. The composition and analysis of the materials are listed in Table 1. In particular, D. Tertiolecta is made up of numerous lipids, carbohydrates and proteins, and the others components are chlorophyll and minerals.

\subsection{Co-liquefaction experiment}

The hydrothermal liquefaction experiment was carried out in a stainless batch autoclave with $50 \mathrm{~mL}$ capacity. Similar to that in a typical liquefaction process, $3 \mathrm{~g}$ of a mixture of microalgae and plastic blended with $30 \mathrm{~mL}$ of deionized water was loaded into the reactor, which was then sealed. The reactor was heated to the target temperature using an electric heating jacket, kept at this temperature for a certain residence time between 0-40 $\mathrm{min}$, and taken out and quickly cooled to room temperature using water.

The separation of the liquefaction products is depicted in Fig. S1 (ESI $\dagger$ ). The products of direct liquefaction include gas, liquid, and solid phases. The gas was vented after the autoclave had cooled. The liquid phase was filtered to separate the waterinsoluble fraction. The water-insoluble fraction and the walls of the autoclave were washed with dichloromethane thrice and the contents were separated through filtration. The dichloromethane was removed in a rotary evaporator at $313 \mathrm{~K}$ under reduced pressure and the remaining dichloromethane phase was called "bio-oil". The water-insoluble fraction remaining on the filter paper was dried at $378 \mathrm{~K}$ for more than $24 \mathrm{~h}$, weighed, and designated as the "residue". Each experiment was repeated 3 times and the average values were reported.

The liquefaction conversion and product yield were calculated as follows:

$$
\begin{aligned}
\text { Yield of bio-oil }= & (\text { weight of bio-oil } \div \text { weight of feedstock }) \\
& \times 100 \% \\
\text { Yield of residue }= & (\text { weight of residue } \div \text { weight of feedstock }) \\
& \times 100 \%
\end{aligned}
$$

Liquefaction conversion $=1-$ Yield of residue.

\subsection{Product analysis}

The character of the bio-oil obtained from the co-liquefaction experiment was analyzed using GC-MS. The analyses were conducted on a 5975C type GC-MS spectrometer (Aglient, USA) equipped with flame ionization detector and HP-5MS column (30 $\mathrm{m} \times 250 \mu \mathrm{m} \times 0.25 \mu \mathrm{m})$. The carrier gas was helium (He) at a flow

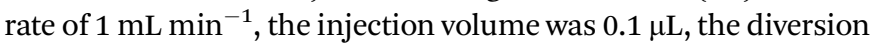
ratio was $50: 1$ and the ionization method used was EI at an electron energy of $70 \mathrm{eV}$. Three minutes of solvent delay was set to protect the filament. The column was held at $60^{\circ} \mathrm{C}$ for $1 \mathrm{~min}$, and then the temperature was raised to $150^{\circ} \mathrm{C}$ using a heating rate of $5{ }^{\circ} \mathrm{C}$ min and held for $5 \mathrm{~min}$. Then, the temperature was increased to $300{ }^{\circ} \mathrm{C}$ at $10{ }^{\circ} \mathrm{C} \mathrm{min}$ and held for $5 \mathrm{~min}$. The total run-time was approximately $44 \mathrm{~min}$. The main peaks of the bio-oil were identified using the NIST08 mass spectral library.

\section{Results and discussion}

\subsection{The influence of the reactant proportion on the liquefaction process}

3.1.1. The influence on the total bio-oil yield. As shown in Fig. 1, the ratio of the two reactants have a significant effect on the total bio-oil yield. When the ratio of PP and D. tertiolecta range from $0: 10$ to $10: 0$, the bio-oil yield and the conversion of reactants reduced almost linearly, while the residue yield rapidly increased. When PP $: D$. tertiolecta $=10: 0$, the yield of bio-oil was only $1.84 \%$, and a large amount of white solid residue was found on the bottom of the reaction kettle after the liquefaction experiment. That is to say, under the current experimental conditions, PP almost does not breakdown. However, under the same reaction conditions, the conversion was as high as $87.87 \%$ when $D$. tertiolecta was liquefied alone (PP : D. tertiolecta $=0: 10$ ) and the yield of bio-oil was $27.42 \%$. 
Table 1 The analysis results for $D$. tertiolecta and PP

\begin{tabular}{|c|c|c|c|c|c|c|c|}
\hline \multicolumn{3}{|c|}{ Industrial analysis/\% } & \multicolumn{3}{|c|}{ Elemental analysis $/ \%$} & \multicolumn{2}{|c|}{$\begin{array}{l}\text { Chemical composition } \\
\text { analysis/\% }\end{array}$} \\
\hline Material & D. tertiolecta & PP & Material & D. tertiolecta & PP & Material & D. tertiolecta \\
\hline Moisture $\mathrm{W}_{\mathrm{ar}}$ & 1.60 & - & $\mathrm{C}$ & 43.31 & 84.55 & Lipids & 5.18 \\
\hline Volatiles $\mathrm{V}_{\mathrm{ar}}$ & 64.70 & 100 & $\mathrm{H}$ & 5.96 & 13.58 & Proteins & 30.63 \\
\hline \multirow{2}{*}{$\begin{array}{l}\text { Ash } A_{\mathrm{ar}} \\
\text { Fixed carbon } \mathrm{C}_{\mathrm{Far}}\end{array}$} & 16.50 & - & $\mathrm{O}^{a}$ & 29.90 & - & Carbohydrates & 52.31 \\
\hline & & & $\mathrm{HHV} / \mathrm{MJ} \cdot \mathrm{kg}^{-1}$ & 17.81 & 45.52 & & \\
\hline
\end{tabular}

The synergistic effect (SE) was used to evaluate the interaction between the two different reactants and calculation formula was as follows:

$$
\mathrm{SE}=\mathrm{Y}_{\mathrm{C}}-\left(\mathrm{X}_{\mathrm{D}} \times \mathrm{Y}_{\mathrm{D}}+\left(1-\mathrm{X}_{\mathrm{D}}\right) \times \mathrm{Y}_{\mathrm{PP}}\right)
$$

where, $\mathrm{Y}_{\mathrm{C}}$ is the total yield of bio-oil, $\mathrm{X}_{\mathrm{D}}$ is the mass fraction of D. tertiolecta in the total reactants, $\mathrm{Y}_{\mathrm{D}}$ and $\mathrm{Y}_{\mathrm{PP}}$ are the oil yield when $D$. tertiolecta and PP was liquefied alone. When SE $>0$, there is a positive correlation between both reactants and the total bio-oil yield of co-liquidation was higher than when the two reactants were liquefied independently. On the contrary, when $\mathrm{SE}<0$, the total bio-oil yield of co-liquidation was lower than when the two reactants were liquefied individually.

The changing tendency of SE with the reactant proportion is shown in Fig. 2. It can be seen from the numerical SE that there exists some interaction between $D$. tertiolecta and PP, but the impact of the interaction on the yield of the target product is not very significant. Upon the addition of PP, the SE reached a maximum of $3.3 \%$ when the ratio of PP and D. tertiolecta was $2: 8$, which demonstrated that the synergy effect between PP and $D$. tertiolecta was strongest at this ratio. When the ratio of $\mathrm{PP}$ and $D$. tertiolecta was $6: 4$, the SE reached a negative value, which showed that at this proportion, the synergy effect is negative between PP and $D$. tertiolecta.

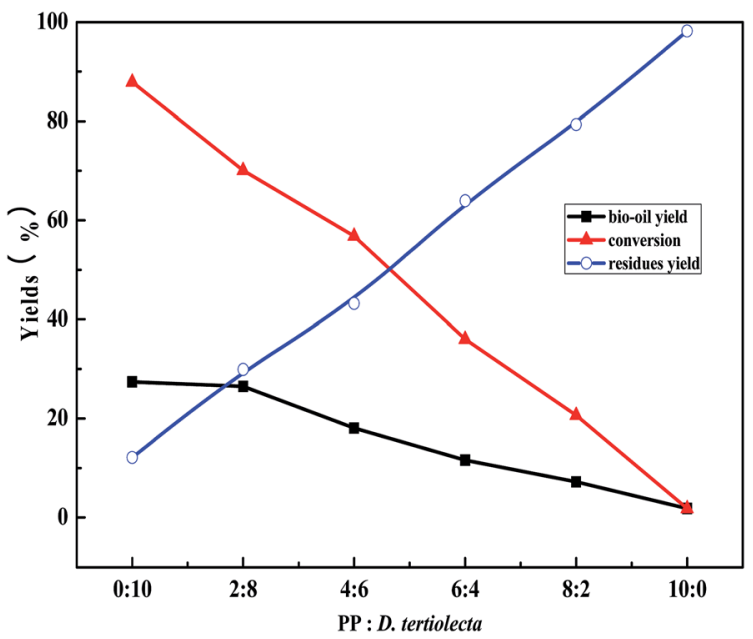

Fig. 1 The influence of reactant proportion on the total bio-oil yield.
3.1.2. The influence on the distribution of bio-oil products. As mentioned above, the purpose of adding PP into the D. tertiolecta HTL system was to improve the quality of the biooil produced, while the chemical composition of bio-oil played a decisive role in its quality. GC-MS was used to characterize the distribution of the bio-oil product and the product components of each group are listed in Table 2. As PP undergoes almost no liquefaction under this experimental condition, no usable data for the PP only liquefied product was detected.

It can be seen that the bio-oil obtained from $D$. tertiolecta was mainly composed of oxygen containing compounds, such as ring ketones, lactones and phenols produced by the decomposition of sugars and fatty acids produced by lipid hydrolysis. Hexadecanoic acid is the most abundant component of the biooil obtained from $D$. tertiolecta, accounting for $18.73 \%$ of the total bio-oil. In addition, 2-hexadecene, 3,7,11,15-tetramethyl-, $\left[R-\left[R^{*}, R^{*}-(E)\right]\right]-$ had the highest content of hydrocarbons, which accounted for $18.07 \%$ of the total bio-oil and originated from the decomposition of chlorophyll whose detailed reaction mechanism will be discussed in Section 3.4.

The distribution of the co-liquefaction bio-oil products was similar to the $D$. tertiolecta liquefaction products and indicated that PP still did not breakdown during the co-liquidation process. However, the addition of PP had a significant effect

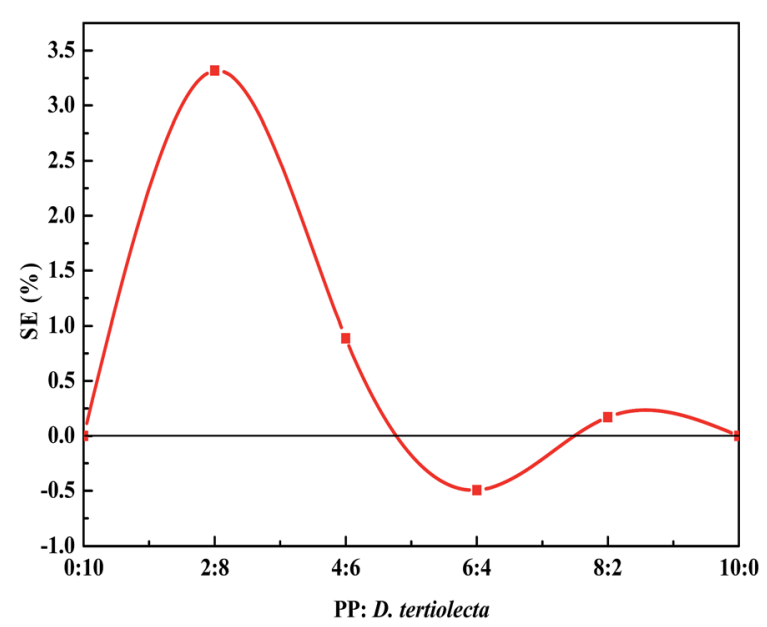

Fig. 2 The changing tendency of SE with the reactant proportion. 
Table 2 The main components of bio-oil obtained from the co-liquidation process with different reactant proportions ${ }^{a}$

\begin{tabular}{|c|c|c|c|c|c|c|c|c|}
\hline \multirow[b]{2}{*}{ Name } & \multirow{2}{*}{$\begin{array}{l}\text { Molecular } \\
\text { formula }\end{array}$} & \multirow{2}{*}{$\begin{array}{l}\text { Structural } \\
\text { formula }\end{array}$} & \multirow{2}{*}{$\begin{array}{l}\text { Time } \\
(\mathrm{RT} / \mathrm{min})\end{array}$} & \multicolumn{5}{|c|}{ Relative amount ${ }^{\Delta}(\%)$} \\
\hline & & & & $0: 10$ & $2: 8$ & $4: 6$ & $6: 4$ & $8: 2$ \\
\hline 2-Cyclopenten-1-one & $\mathrm{C}_{5} \mathrm{H}_{6} \mathrm{O}$ & & 3.6 & - & - & 1.95 & 2.93 & 6.26 \\
\hline Cyclopentanone, 2-methyl- & $\mathrm{C}_{6} \mathrm{H}_{10} \mathrm{O}$ & & 3.7 & 1.54 & - & - & - & - \\
\hline 2-Cyclopenten-1-one, 2-methyl- & $\mathrm{C}_{6} \mathrm{H}_{8} \mathrm{O}$ & & 4.8 & 3.21 & 4.67 & 6.36 & 8.32 & 8.81 \\
\hline 2-Cyclopenten-1-one, 3-methyl- & $\mathrm{C}_{6} \mathrm{H}_{8} \mathrm{O}$ & & 6.0 & 3.25 & 4.49 & 5.60 & 7.01 & 9.11 \\
\hline Phenol & $\mathrm{C}_{6} \mathrm{H}_{5} \mathrm{OH}$ & & 6.3 & 2.86 & 3.47 & 3.29 & 3.31 & 3.51 \\
\hline 2,3-Dimethyl-2-cyclopenten-1-one & $\mathrm{C}_{7} \mathrm{H}_{10} \mathrm{O}$ & & 7.8 & 1.62 & 4.77 & 2.47 & 4.33 & 2.00 \\
\hline Phenol, 4-methyl- & $\mathrm{C}_{7} \mathrm{H}_{8} \mathrm{O}$ & & 8.7 & 2.43 & 4.85 & 4.70 & 4.64 & 4.70 \\
\hline $\begin{array}{l}\text { 2(4H)-Benzofuranone, 5,6,7,7a-tetrahydro- } \\
4,4,7 \mathrm{a} \text {-trimethyl- }\end{array}$ & $\mathrm{C}_{11} \mathrm{H}_{16} \mathrm{O}_{2}$ & & 20.9 & 7.63 & 7.00 & 7.73 & 9.55 & 9.94 \\
\hline Cyclohexanone, 2,2,6-trimethyl- & $\mathrm{C}_{9} \mathrm{H}_{16} \mathrm{O}$ & & 7.7 & - & 1.53 & - & - & - \\
\hline Butyrolactone & $\mathrm{C}_{4} \mathrm{H}_{6} \mathrm{O}_{2}$ & & 4.9 & - & - & - & 1.84 & 2.74 \\
\hline 1,2-Cyclopentanedione, 3-methyl- & $\mathrm{C}_{6} \mathrm{H}_{8} \mathrm{O}_{2}$ & & 7.5 & - & - & - & - & 4.55 \\
\hline Pyrazine, methyl & $\mathrm{C}_{5} \mathrm{H}_{6} \mathrm{~N}_{2}$ & & 3.4 & - & - & 1.02 & 1.28 & - \\
\hline 2-Pyrrolidinone & $\mathrm{C}_{4} \mathrm{H}_{7} \mathrm{NO}$ & & 8.4 & 3.06 & 2.82 & 3.54 & 3.21 & 3.82 \\
\hline 2,5-Pyrrolidinedione, 1-methyl- & $\mathrm{C}_{5} \mathrm{H}_{7} \mathrm{NO}_{2}$ & & 9.1 & 2.26 & 2.06 & 2.67 & 3.28 & - \\
\hline 3-Pyridinol, 6-methyl- & $\mathrm{C}_{6} \mathrm{H}_{7} \mathrm{NO}$ & & 10.8 & 5.52 & 5.14 & - & 8.57 & 9.71 \\
\hline 9H-Pyrido[3,4-b]indole, 1-methyl- & $\mathrm{C}_{12} \mathrm{H}_{10} \mathrm{~N}_{2}$ & & 31.0 & 3.60 & 3.22 & 3.32 & 1.79 & - \\
\hline 9H-Pyrido[3,4- $b]$ indole & $\mathrm{C}_{11} \mathrm{H}_{8} \mathrm{~N}_{2}$ & & 31.1 & 1.94 & 2.46 & 2.90 & 1.96 & 1.66 \\
\hline 2,5-Piperazinedione, 3-benzyl-6-isopropyl- & $\mathrm{C}_{14} \mathrm{H}_{18} \mathrm{~N}_{2} \mathrm{O}_{2}$ & & 33.8 & 4.32 & 3.32 & 4.71 & 5.82 & 4.99 \\
\hline $\begin{array}{l}\text { Pyrrolo[1,2-a]pyrazine-1,4-dione, hexahydro-3- } \\
\text { (phenylmethyl)- }\end{array}$ & $\mathrm{C}_{14} \mathrm{H}_{16} \mathrm{~N}_{2} \mathrm{O}_{3}$ & & 34.9 & 4.68 & 3.94 & 5.01 & 5.75 & 5.76 \\
\hline
\end{tabular}


Table 2 (Contd.)

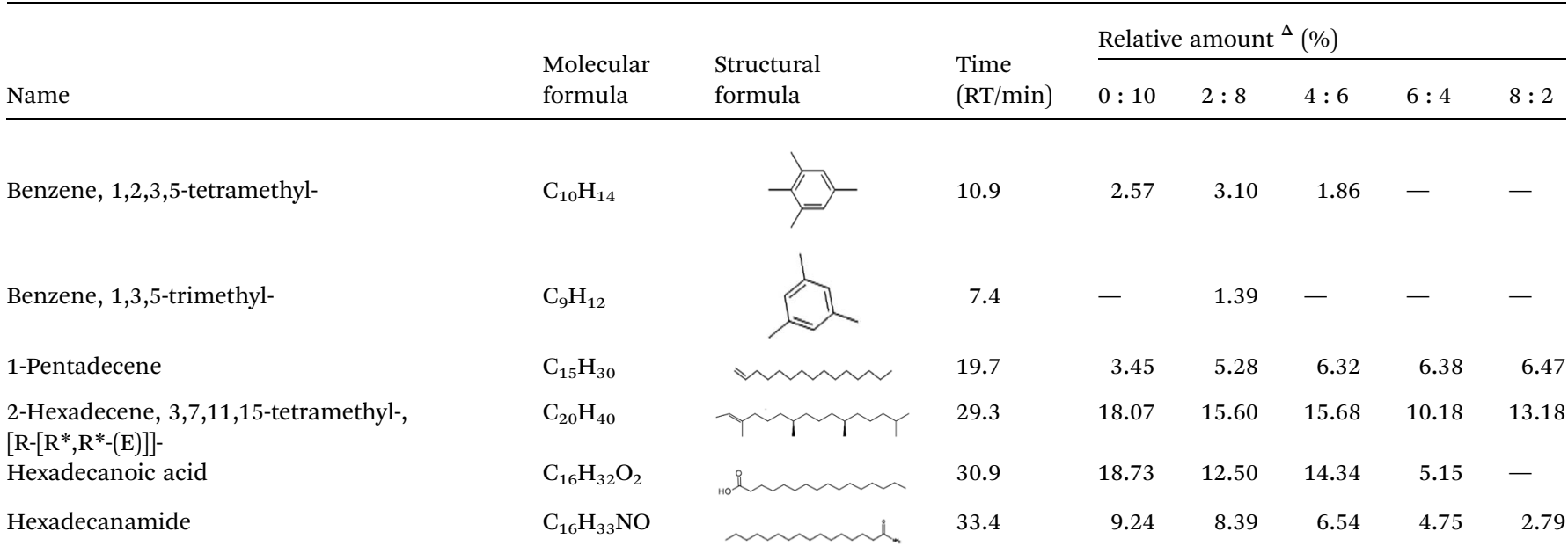

${ }^{a \Delta}$ Only compounds with a confidence level higher than 80 were counted, the relative content of the compounds was calculated according to the peak area of the GC-MS ion flow diagram. The relative amount in the table refer to PP : D. tertiolecta.

on the content of each bio-oil component. As can be seen in Table 2, the addition of PP can promote the formation of ketone compounds. Upon increasing the PP content in the reactants, the content of five-membered ring ketone compounds in the bio-oil products was significantly increased, which means that PP had a significant impact on the decomposition pathway of the sugars in the microalgae. In addition, it is worth noting that the addition of PP significantly decreased the content of hexadecanoic acid in the bio-oil product. This may indicate that PP interacts with hexadecanoic acid during the co-liquidation process, but products of hexadecanoic acid decarboxylation were not detected in the bio-oil product. In our previous study, we found that $\mathrm{PP}$ can react with carbonyl compounds in D. tertiolecta and reduce the output of $\mathrm{CO}_{2} \cdot{ }^{16}$ The conclusion that can be made is that some hexadecanoic acid may have reacted with PP and produced macromolecular coking and water. However, this specific process needs further experimental research.

Similarly, the proportion of reactants has a great influence on the composition of bio-oil and the data in Table 2 were classified by the category of compounds such as carbonyl compounds, nitrogen compounds, hydrocarbons and acids in order for clarity. This classification was based on the source of each compound, such as carbonyl compounds (ketone, esters etc.) were mainly produced by the decomposition of sugar and nitrogen compounds were mainly produced from protein decomposition, acids resulted from lipid hydrolysis and hydrocarbons were produced by the deoxygenation of oxygen compounds or denitrification of nitrogen compounds. The classification results are shown in Fig. 3. It can be seen that the content of carbonyl compounds increased with the proportion of PP in the reactants, whereas the content of acid decreased. When the ratio of PP and D. tertiolecta was $8: 2$, the acid content in the bio-oil products was lower than the detection limit of GC-MS (lower than $100 \mathrm{ppm}$ ).

\subsection{The influence of reaction temperature on the liquefaction process}

3.2.1. The influence on the total bio-oil liquid yield. Fig. 4 shows the changing trends for the reaction yield and conversion with the reaction temperature. It can be seen that the bio-oil yield and conversion increase with an increase in temperature from $320{ }^{\circ} \mathrm{C}$ to $340{ }^{\circ} \mathrm{C}$ and when increased from $340{ }^{\circ} \mathrm{C}$ to $370{ }^{\circ} \mathrm{C}$, the yield and conversion decrease first then increase. This was consistent with that reported in the literature ${ }^{17,18}$ and was attributed to the liquefaction process including the decomposition of the reactants and the polymerization reaction of the decomposition products; increasing the reaction temperature promoted the decomposition of the reactants as well as the polymerization of the intermediates. In addition,

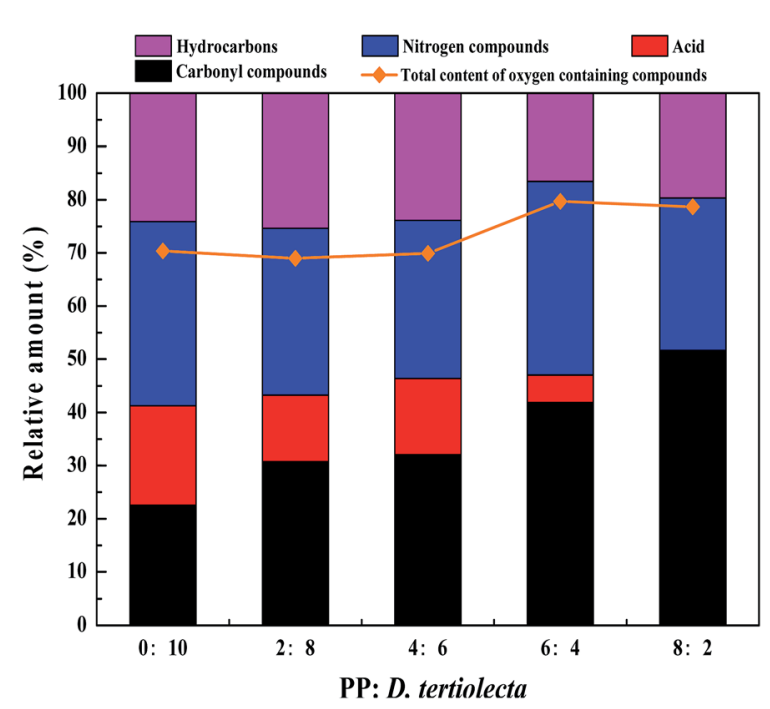

Fig. 3 The relative content of each compound in the bio-oil produced with different proportions of the reactants. 


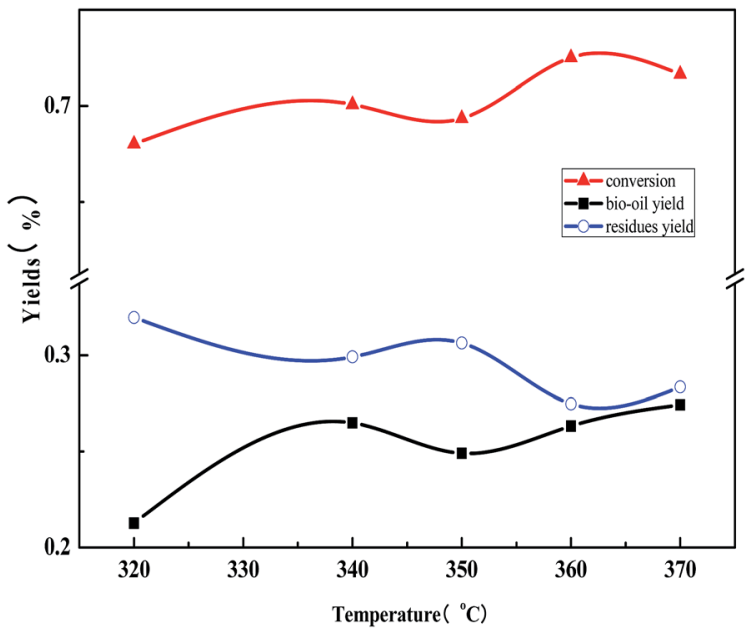

Fig. 4 The influence of reaction temperature on the bio-oil yield.

increasing the temperature could improve the solvent effect of water and promote the decomposition of the reactants.

3.2.2. The influence on the distribution of the bio-oil products. In accordance with Section 3.1.2, the components of the bio-oil were divided into four categories and the classification results are shown in Fig. 5 . It can be seen that the reaction temperature has a significant impact on the acid content of the bio-oil product. At $340{ }^{\circ} \mathrm{C}$, the acid content was the lowest $(12.50 \%)$ in the bio-oil product and in the temperature range from $350{ }^{\circ} \mathrm{C}$ to $370{ }^{\circ} \mathrm{C}$, the acid content was higher than $20 \%$. The total content of oxygen containing compounds in the biooil product generally presents a decreasing trend with an increase in temperature (except at $350{ }^{\circ} \mathrm{C}$ ). This shows that high temperature was more advantageous to the deoxidization reaction. Hydrocarbons are one of the most desired liquefaction products and the hydrocarbon content showed a slight increase upon increasing the temperature and was at a maximum at $360{ }^{\circ} \mathrm{C}(26.67 \%)$.

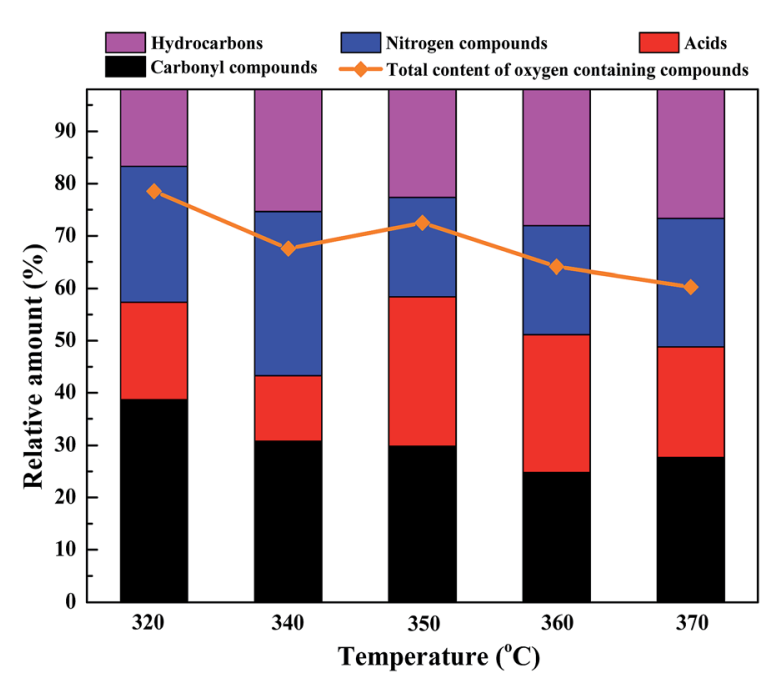

Fig. 5 The relative content of each compound in the bio-oil produced at different temperatures.

\subsection{The influence of residence time on the liquefaction process}

3.3.1. The influence on the total bio-oil liquid yield. In this study, the residence time means the time maintained after reaching the reaction temperature $\left(340{ }^{\circ} \mathrm{C}\right)$. Fig. 6 shows the changing tendency of the bio-oil yield and conversion with residence time. It can be seen that the conversion and the biooil yield were increased upon increasing the reaction time and this trend gradually flattened out. The bio-oil yield reached a maximum $(26.90 \%)$ when the residence time was $40 \mathrm{~min}$. The bio-oil yield increased by $2.73 \%$ when compared with the yield at 0 min and only increased by $0.48 \%$ when compared with the yield at $30 \mathrm{~min}$, which indicated that the decomposition of reactants was dominant within $40 \mathrm{~min}$ when compared with the coking reaction of the products and this superiority gradually weakened upon increasing the residence time.

3.3.2. The influence on the distribution of bio-oil products. The GC-MS analysis results of the bio-oils obtained from the liquefaction at different residence times are shown in Fig. S2 (ESI $\dagger$ ). It can be seen that the composition of bio-oil was basically stable after $10 \mathrm{~min}$; that is to say, upon extending the reaction time, the composition of bio-oil no longer changed and only changes in the contents of each component were observed. At the same time, components with a high boiling point and long retention time reduce gradually, while substances with a low boiling point increase gradually. This suggests that the macromolecular compounds (long chain amide, amino acids, etc.) start to breakdown and smaller molecules are generated.

The main reactions, which occurred between $0 \mathrm{~min}$ and $10 \mathrm{~min}$, are the conversion of furfural materials. It can be seen that when comparing the ion chromatograms, the product at 0 min contains a large amount of furfural and its derivatives, such as furfural $(\mathrm{RT}=3.6), 2$-furancarboxaldehyde, 5-methyl$(\mathrm{RT}=6.0), 2$-cyclopenten-1-one, 2-hydroxy-3-methyl- $(\mathrm{RT}=$ 7.5), 2-furancarboxaldehyde, 5-(hydroxymethyl)-(5-HMF, RT = 12.8). However, no aldehydes existed in the product at $10 \mathrm{~min}$; most aldehydes were turned into residues and a small proportion was transformed into ketones, lactones, and phenols or reacted with $\mathrm{N}$-containing compounds and

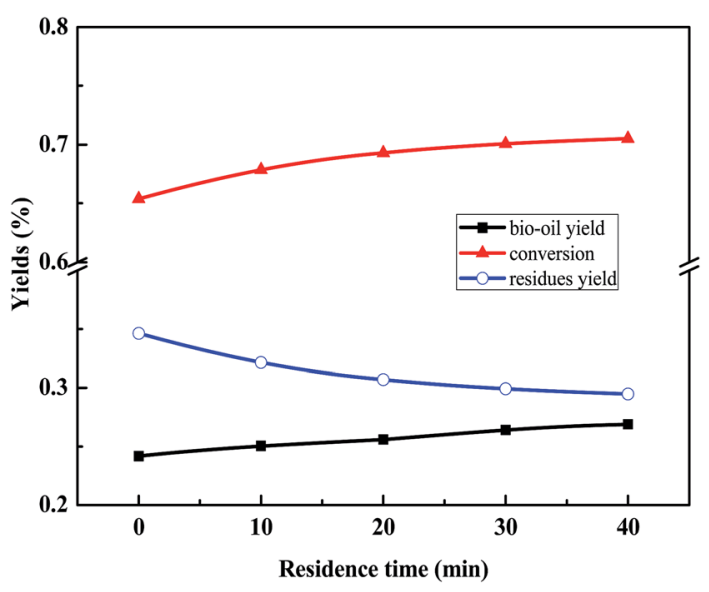

Fig. 6 The influence of residence time on the bio-oil yield. 
proteins, generating hydroxyl pyridine ring, pyrrolidone, and amide compounds.

The changes in the contents of the bio-oil components are shown in Fig. 7. It can be seen that the total N-containing compounds increased after $10 \mathrm{~min}$, corresponding to the decomposition of most of the proteins. Upon increasing the residence time the amount of acid in the bio-oil product reduced and the hydrocarbon content increased gradually. It is worth noting that the total amount of oxygenated chemicals was almost equal to the sum of aldehyde, ketones, acid, ester and $\mathrm{N}$ containing compounds before $30 \mathrm{~min}$ and illustrated that all the N-containing compounds contained oxygen (called N\&O compounds) at this time. After $30 \mathrm{~min}, \mathrm{~N}$-containing compounds containing no oxygen, such as indole, began to be generated. Moreover, the total oxygenated chemicals in the bio-oil product decreased from $92.56 \%$ to $68.95 \%$ and the hydrocarbon content increased from $7.43 \%$ to $25.36 \%$. It can be concluded that the main reason for the decrease in the oxygenated chemicals in biooil was the deoxygenation reaction of the oxygenated compounds, such as ketones, phenols and esters, leading to the formation of hydrocarbons before $30 \mathrm{~min}$. In contrast, it was more difficult to deoxygenate the $\mathrm{N}$ and $\mathrm{O}$ compounds.

\subsection{Analysis mechanism of the co-liquefaction process}

3.4.1. The change in the product components in the temperature-rise period of the liquefaction process. The changes in the bio-oil components during the holding time after reaching the reaction temperature were discussed in Section 3.3.2 and the results indicated that the main reactions occurring during the holding time included the protein decomposition process, aggregation and deoxidization reactions of the intermediates derived from carbohydrates and proteins. The decomposition of carbohydrates occurs before reaching the reaction temperature and in order to examine the decomposition process of carbohydrates, the change in bio-oil

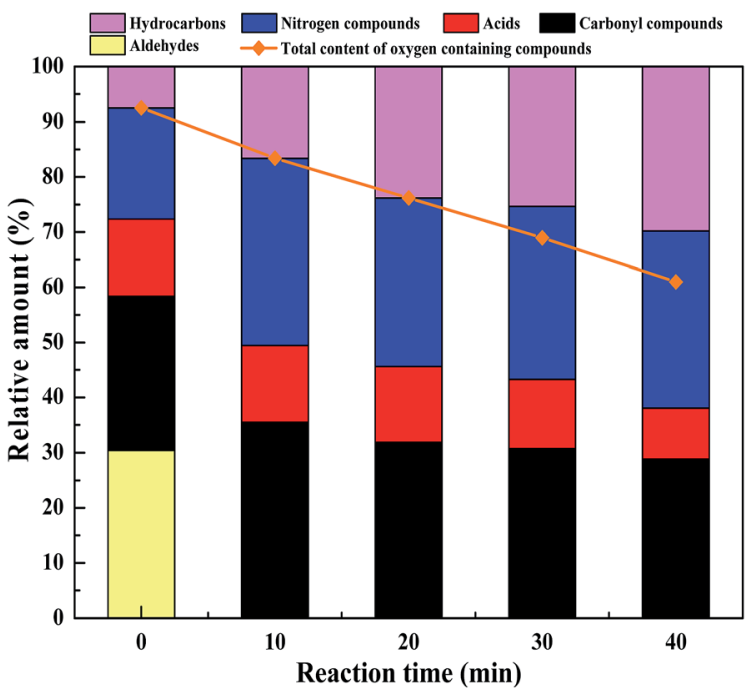

Fig. 7 The relative content of each compound in the bio-oil produced after different residence times. components during the holding time were analyzed. The results are shown in Fig. S5 and Table S1 (ESI $\dagger$ ).

It can be seen from Fig. $\mathrm{S} 3 \uparrow$ that lipid decomposition begins before $260{ }^{\circ} \mathrm{C}$ and produces hexadecanoic acid ( $\left.\mathrm{RT}=30.97\right)$. Moreover, some methyl hexadecanoate $(\mathrm{RT}=30.4)$ and triethyl citrate $(\mathrm{RT}=25.6)$ existed in the reaction system, which may have come from esterification reaction of acid and alcohols (produced by the decomposition of glycerin or reduction of amino acids). Carbohydrate decomposition occurred in large amounts after $280{ }^{\circ} \mathrm{C}$ with the main product being 5 - $\mathrm{HMF}(\mathrm{RT}=$ 12.8). The content of 5 -HMF reached a maximum $(59.69 \%)$ at $300{ }^{\circ} \mathrm{C}$. 5-HMF has a high activity for polymerization and easily cokes leading to a rapid reduction in the 5-HMF content as the temperature increases. The content of 5-HMF dropped to $13.40 \%$ when the temperature reached $340{ }^{\circ} \mathrm{C}$ and the content of hexadecanoic acid began to decrease at this temperature.

3.4.2. Speculation of the main reaction route in the coliquidation process. $\mathrm{PP}$ showed almost no decomposition at $340{ }^{\circ} \mathrm{C}$, and therefore in this study, the reaction of $D$. tertiolecta was dominant during the co-liquidation process, and the existence of PP had an evident effect on the bio-oil composition. The primary components of $D$. tertiolecta can be divided into three categories including lipids, carbohydrates and proteins, and combining with the analysis of the above sections, their reaction routes are discussed below:

(1) Lipids. Lipids in microalgae usually refer to the triglyceride fatty acids, which have a poor thermal stability and are hydrolyzed to produce fatty acids and glycerin at low temperatures. It can be seen from Table $\mathrm{S} 1 \dagger$ that tripalmitin was the main lipid composition in $D$. tertiolecta. The hydrolysate of tripalmitin is hexadecanoic acid, which has a high stability under hydrothermal conditions. However, the decarboxylation of hexadecanoic acid can still occur when the temperature is high enough and produces hydrocarbons.

The main reaction route for lipids is shown in Fig. 8. During the temperature-rise period, lipid hydrolysis generated glycerol and fatty acids, while glycerol hydrolysis produced small molecules of alcohols, such as methanol, which then react with the fatty acids to produce fatty acid esters at $200{ }^{\circ} \mathrm{C}$ (methyl hexadecanoate, $\mathrm{RT}=30.4)$. Ester hydrolyzed completely when the temperature reached $280{ }^{\circ} \mathrm{C}$ (Table $\mathrm{S} 1 \dagger$ ). When temperature increased to $340{ }^{\circ} \mathrm{C}$, fatty acids started to react with $\mathrm{NH}_{3}$ (produced by decomposition of protein) and produced amides (hexadecanamide, $\mathrm{RT}=33.4$ ); at the same time, because of the existence of PP, a large amount of the acids reacted with PP and turned into residues (Table 2), while a part of the acids were decarboxylated during the holding time and produced $\mathrm{CO}_{2}$ and hydrocarbons with the loss of one carbon atom.

It is worth mentioning that the hydrocarbons in bio-oil are generally recognized as the decarboxylated products of acids. However, in this study, the main hydrocarbon ingredient (2hexadecene, 3,7,11,15-tetramethyl-, [R-[R*, $\left.\left.\left.\mathrm{R}^{*}-(\mathrm{E})\right]\right]-\right)$, which accounted for more than $60 \%$ of the total hydrocarbons, originated from the decomposition of chlorophyll. Chlorophyll was esterified by a porphyrin ring and leaf alcohol $(3,7,11,15-$ tetramethyl-2-hexadecen-1-ol) and hydrolyzed at a low temperature to produce leaf alcohol. However, the leaf alcohol began to 

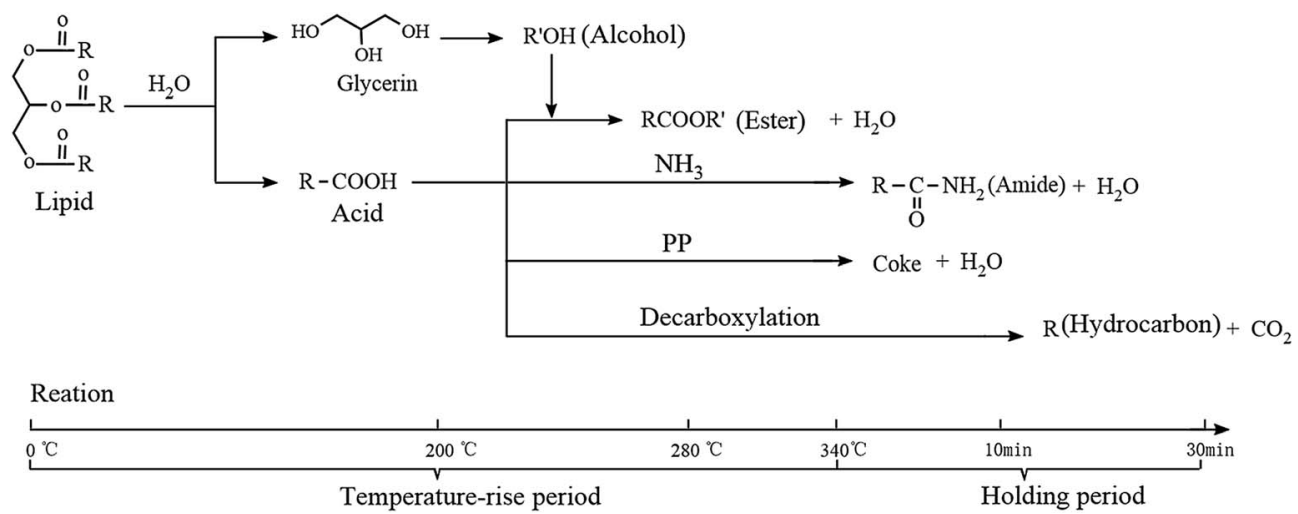

Fig. 8 The main reaction routes for lipids.

dehydrate after $320^{\circ} \mathrm{C}$ and generated 2-hexadecene, 3,7,11,15tetramethyl-, $\left[\mathrm{R}-\left[\mathrm{R}^{*}, \mathrm{R}^{*}-(\mathrm{E})\right]\right]-$. The specific reaction pathways are shown in Fig. S4 (ESI†).

(2) Carbohydrates and proteins. Fig. 9 shows the reaction routes for carbohydrates and proteins. In the HTL process, the carbohydrates and proteins were hydrolyzed at a low temperature (before $200{ }^{\circ} \mathrm{C}$ ) to produce monosaccharides and amino acids, respectively. Monosaccharides have two main reaction routes, one is the conversion into the furfural class materials and then in to residues. This particular process was discussed in Section 3.4.1. The other reaction route is the production of cyclopentenone derivatives. It can be seen from Table 2 that the content of cyclopentene derivatives in bio-oil increased upon increasing the proportion of PP and included 2-methyl-2- cyclopenten-1-one, the content of which ranged from 3.21 to 8.81 when the mass ratio of PP and $D$. tertiolecta increases from $0: 10$ to $8: 2$, respectively. The addition of PP produced carbohydrate and further resulted in cyclopentenone derivatives, which reduced coking indirectly.

Amino acids produced by protein hydrolysis can be decomposed to $\mathrm{NH}_{3}, \mathrm{CO}_{2}$, carboxylic acids and amines, or produce an annular amide (e.g. 2,5-piperazinedione, 3-benzyl-6-isopropyl-, $\mathrm{RT}=33.8)$ via condensation. Carbohydrates and proteins and their hydrolysates can react to generate $\mathrm{N} \& \mathrm{O}$ compounds such as pyridine and pyrazine. This type of reaction is called the Maillard reaction. From the perspective of product composition (see Table 2), the addition of PP has a certain role in promoting the Maillard reaction, which has not been reported in literature.

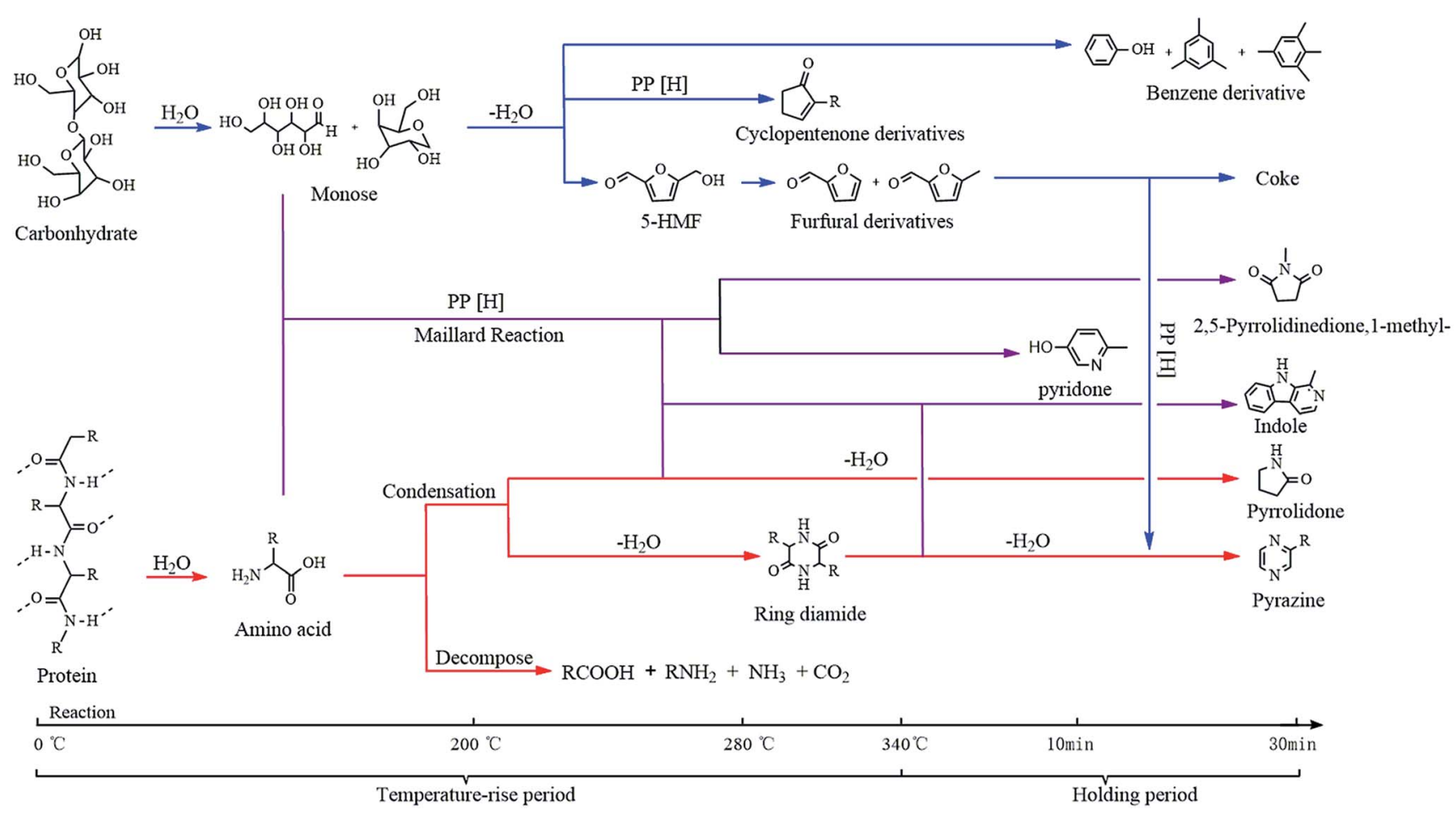

Fig. 9 The reaction routes for carbohydrates and proteins. 
Generally speaking, in the co-liquefaction process, PP is not directly involved in the conversion of carbohydrates and proteins, but the existence of PP can have a significant effect on the decomposition route of carbohydrates and promote the Maillard reaction. This may be attributed to the hydrogen donating ability of PP and the specific effect of PP will be investigated in further studies.

\section{Conclusion}

The co-liquefaction process of $D$. tertiolecta and PP was investigated in this study, the main results show that the addition of PP mainly impacts the composition of bio-oil, which significantly improves the bio-oil quality. At the same time, the reaction mechanism of the co-liquefaction process was investigated, which showed that PP can affect the liquefaction mechanism of D. tertiolecta.

The influence of PP is mainly in (1) greatly reducing the acid content in bio-oil, (2) significantly affecting the transformation pathways of carbohydrates to produce more cyclopentenone derivatives and (3) promoting the Maillard reaction between carbohydrates and proteins or their hydrolysates.

\section{Acknowledgements}

This study was supported by the National Natural Science Foundation of China (No. 21576155, 21376140 and 21176142), the Research Project of Guangdong Provincial Department of Science and Technology Department (No. 2015B020215004), the Program for Changjiang Scholars and the Innovative Research Team in University (IRT13026) and the Program for New Century Excellent Talents in University (No. NCET-12-0308).

\section{References}

1 A. A. Upadhye, W. Qi and G. W. Huber, AIChE J., 2011, 57, 2292-2301.
2 C. C. Zhang, P. G. Duan, Y. P. Xu, B. Wang, F. Wang and L. Zhang, Bioresour. Technol., 2014, 166, 37-44.

3 Y. Chen, Y. L. Wu, P. L. Zhang, D. R. Hua, M. D. Yang, C. Li, Z. Chen and J. Liu, Bioresour. Technol., 2012, 124, 190-198.

4 Y. Guo, Z. Yuanhui, G. Bin, T. Funk and L. Schideman, BioEnergy Res., 2014, 7, 1317-1328.

5 S. P. Zou, Y. L. Wu, M. D. Yang, C. Li and J. M. Tong, Bioresour. Technol., 2010, 101, 359-365.

6 M. Negoro, A. Hamasaki, Y. Ikuta, T. Makita, K. Hirayama and S. Suzuki, Appl. Biochem. Biotechnol., 1993, 39, 643-653.

7 N. Marin, S. Collura, V. I. Sharypov, N. G. Beregovtsova, S. V. Baryshnikov, B. N. Kutnetzov, V. Cebolla and J. V. Weber, J. Anal. Appl. Pyrolysis, 2002, 65, 41-55.

8 B. Han, Y. Chen, Y. L. Wu, D. R. Hua, Z. Chen, W. Feng, M. D. Yang and Q. H. Xie, J. Therm. Anal. Calorim., 2014, 115, 227-235.

9 P. Bhattacharya, P. H. Steele, E. B. M. Hassan, B. Mitchell, L. Ingram and C. U. Pittman, Fuel, 2009, 88, 1251-1260.

10 E. Jakab, G. Varhegyi and O. Faix, J. Anal. Appl. Pyrolysis, 2000, 56, 273-285.

11 M. Brebu, S. Ucar, C. Vasile and J. Yanik, Fuel, 2010, 89, 1911-1918.

12 L. Sorum, M. G. Gronli and J. E. Hustad, Fuel, 2001, 80, 12171227.

13 K. J. Wu, J. Liu, Y. L. Wu, Y. Chen, Q. H. Li, X. Xiao and M. D. Yang, Bioresour. Technol., 2014, 163, 18-25.

14 X. Y. Wu, Y. L. Wu, K. J. Wu, Y. Chen, H. S. Hu and M. D. Yang, Bioresour. Technol., 2015, 192, 522-528.

15 X. K. Pei, X. Z. Yuan, G. M. Zeng, H. J. Huang, J. Y. Wang, H. Li and H. N. Zhu, Fuel Process. Technol., 2012, 93, 35-44.

16 P. G. Duan, B. B. Jin, Y. P. Xu and F. Wang, Chem. Eng. J., 2015, 269, 262-271.

17 C. Gai, Y. Li, N. N. Peng, A. N. Fan and Z. G. Liu, Bioresour. Technol., 2015, 185, 240-245.

18 C. Gai, Y. H. Zhang, W. T. Chen, P. Zhang and Y. P. Dong, Energy Convers. Manage., 2015, 96, 330-339. 